The view that agents which inhibit the Pasteur effect do so by affecting cell permeability is readily acceptable in the case of potassium. It is an old suggestion $^{3}$ that metal ions may affect cell surfaces by converting a water-in-oil emulsion to an oil-inwater emulsion. The fact that the inhibition of the Pasteur effect, brought about by potassium, is reversed by calcium is a point, on the whole, in favour of such a hypothesis; thus we found that a $Q_{\mathrm{L}}^{0}$ of 16.5 in presence of glucose and $M / 10$ potassium chloride was reduced to $2 \cdot 0$ by addition of $M / 20$ calcium chloride, though addition of sodium chloride in the same concentration did not reverse the potassium effect. Further, we found that rubidium and cæsium had a similar effect to potassium in causing aerobic glycolysis. Values of $Q_{\mathrm{L}}^{\mathrm{O}_{2}}$ on the same brain in the presence of $M / 10$ concentration of the chlorides of these metals were, for potassium $10 \cdot 3$, for rubidium $10 \cdot 35$ and for cæsium $5 \cdot 85$, while for magnesium a value of 2.9 was obtained.

In view of the present evidence, we consider that in the absence of oxygen, the permeability of the cell is so altered (see Cowan ${ }^{4}$ ) that the enzymes are completely accessible to glucose. The enzymes are saturated, and the rate of lactic acid formation becomes maximum. In the presence of oxygen the enzymes are much less accessible to the substrate. Glucose reaches the enzymes relatively slowly, and lactate is either not formed, or is formed at a slower rate than that at which it can be oxidised. If lactate be the substrate added, it too can only slowly gain access to the enzymes, and therefore its rate of removal is relatively low except when potassium is added.

Kendal Dixon. Eric Holmes.

Sir William Dunn Institute of Biochemistry, Cambridge. May 15.

1 Ashford and Dixon, Biochem. J., 29, 157 ; 1935.

Ashrord and Dixon, Biochem.
Dixon, Biochem. J. 29, 973; 1935.
Clowes, J.Phys. Chem., 20, 407; 1916.

' Cowan, Proc. Roy. Soc., B, 115, 216; 1934.

\section{Statistical Aspect of the Production of Primary Lesions by Plant Viruses}

As analogy has frequently been drawn between the production of bacterial colonies on artificial media and of primary lesions on the leaves of susceptible host plants inoculated with an extract of virusdiseased tissues. In a recent paper, Youden, Beale and Guthrie ${ }^{1}$ have carried this analogy one step further, and have suggested that the relation between the numbers of lesions and the relative concentrations of virus particles in the inoculum may be described in the same way as the relation between the numbers of bacterial colonies and the concentration of bacteria in the plated suspension. Their equation takes the form :

$$
y=N\left(1-e^{-a x}\right)
$$

where $y$ is the number of lesions given at any concentration $x$ of the virus, $N$ represents the maximum lesions obtainable, and $a$ is a constant.

There is no reason to doubt that this equation is fundamentally correct, but there is good reason to doubt whether it applies to the majority of the dilution data which they have collected from various published papers and cited in proof of agreement
(Ref. 1, Table II). If the values for low dilutions are fitted by this equation, the calculated values for higher dilutions are almost uniformly too small, and sometimes, as in the following case quoted by Youden, Beale and Guthrie from a paper by Samuel and myself ${ }^{2}$, the differences are far beyond the limits of the experimental error:

\section{Lesions observed. \\ Lesions calculated by Youden, \\ Beale and Guthrie.}

1214474704314336320101003

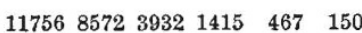

The standard error of the total 1003, for example, is $79 \cdot 4$. Youden, Beale and Guthrie, in transcribing this series, omitted the two figures for the weakest concentrations; they are 477 and 234, and the calculated values would be approximately 48 and 15

As proof of agreement, these authors plot values of $\log (N-y)$ against concentration and show that, in the cases they choose for the purpose of illustration, the values fall approximately on a straight line. This gives a misleading idea of the goodness of fit, as when $N$ is much greater than $y, y$ may vary widely without causing wide departures from a straight line. About two years ago, attempts were made to apply this equation to a series of experiments performed by Mr. Samuel and myself in which samples of crude juice from plants diseased with tobacco mosaic were diluted with distilled water. The more accurate the experiment and the wider the dilution range it covered, the more apparent it became that under our conditions the relation of lesions to concentration could not be described in these terms. For some time I have been working to find under what conditions the equation does apply, and to what departures are due; briefly, it applies only to very carefully purified suspensions of virus. Distortions exist with samples which are carried to that stage of purification where only slight pigmentation remains.

It is doubtful, therefore, what meaning can be attached to the constants calculated by Youden, Beale and Guthrie from equations that fit only portions of the dilution series; and until this has been decided the equation derived from the Poisson series should not be used for the correction of results obtained by the primary lesion method except with very carefully purified samples of viruses. J. G. BALD

(Australian Council for Scientific and Industrial Research).

\section{Botany School,}

\section{Cambridge.}

May 13.

1 Youden, Beale and Guthrie, Contrib. Boyce Thomson Inst., 7, 37; 1935.

'Samuel and Bald, Ann. Appl. Biol., 20, 70; 1933.

\section{The Dyestuff Industry}

I FEAR that Prof. Armstrong is very angry with me (NATURE, June 1, p. 907); for with him such phrases as "management and commercial side", "commercial community", "commercial outlook", "commercial mind" are of course terms of comprehensive opprobrium, and lie at the opposite end of the scale to such mellifluous, desirable and creditable phrases like "true technical leadership". Perhaps after all I do deserve his anger, for he says "I have more than once discussed the situation, most recently in an article in the Pharmaceutical Journal". As I regularly read most of what Prof. Armstrong writes, 